\title{
Effects of Production and Ingredients on Tahini Halvah Quality
}

Oručević Žuljević Sanja ${ }^{1}$, Mutap Naira ${ }^{2}$, Nermina Spaho ${ }^{1}$, Tahmaz Jasmina ${ }^{1}$, Asima Akagić ${ }^{1}$ and Amela Džafić1 1 Food Technology Department, Faculty of Agriculture and Food Sciences, University of Sarajevo, Sarajevo 71000, Bosnia and Herzegovina

2 GA-ME-HA d.o.o. Sarajevo 71000, Bosnia and Herzegovina

\begin{abstract}
Tahini halvah is specific confectionery product known in Bosnia and Herzegovina over centuries. It is made of sesame-seed paste (tahini), sugar and soapwort (Saponaria officinalis) extract by certain technological process, with creating needle-like particles which give a specific fiber structure to halvah. Production of tahini halvah in Bosnia and Herzegovina mostly was placed under artisanal conditions by poorly trained staff and was based on experiences and established practice. There is a very few scientific papers deal with ways of production and specific properties of this product in Bosnia and Herzegovina. Main objective of this paper was focused on studying technological process of 4 different samples of tahini halvah (standard tahini halvah, tahini halvah with pistachios, tahini halvah with cacao and black halvah with wheat grits, cacao and nuts). All samples were produced under industrial conditions. Chemical and sensory quality parameters of investigated samples were presented in this paper. Significant differences between samples were found and influenced by different ingredients and technological process.
\end{abstract}

Key words: Tahini halvah, chemical and sensory quality.

\section{Introduction}

Tahini halvah (TH) is specific confectionery product widely used in Bosnia and Herzegovina over centuries and is available in different forms and flavors. It's a greasy product due to high share of tahini paste which contains more than $50 \%$ sesame oil. Structure of tahini halvah is fragile and brittle [1].

This product has a long history originates from the 16th centiries when came in Bosnia during The Ottoman Empire governing. Tahini halvah was very popular, even a small street in old part of Sarajevo called Halvadžiluk — the confectionary bazaars, was existed until 1908 [2].

Tahini halvah is olso served across South Asia, Central Asia, Asia, North Africa, Balkans, Central Europe, Eastern Europe, and Malta.

In Bosnia and Herzegovina tahini halvah is usually made of sesame-seed paste (tahini), sugar and

Corresponding author: Orucevic Zuljevic Sanja, Ph.D., associate professor, research field: confectionary technology. soapwort (Saponaria officinalis) extract by certain technological process, with creating needle-like particles which give a specific fiber structure to halvah. Production of tahini halvah was placed mostly under artisanal conditions by poorly trained staff and was based on experiences and established practice, as family's handicraft production.

Sesame seeds, as the main ingredients, add a nutty taste and a delicate aroma to this product. Besides making tahini and halvah sesame seeds are used for the preparation of rolls, crackers, cakes and pastry products in commercial bakeries [3].

Sesame seeds were one of the first crops processed for oil as well as one of the earliest condiments. Currently, the largest commercial producers of sesame seeds include India, China and Mexico [4]. Sesame in Turkey is the most important annual oil crop and there are numerous varieties and ecotypes of sesame adapted to various ecological conditions [5]. Proximate composition of Turkish sesame seeds and characterization of their oils have investigated, also 
However, there is still a very few scientific papers deal with ways of production and specific properties of tahini halvah. In Bosnia and Herzegovina this issue has never been seriously investigated.

According to regulations of confectionary quality in Bosnia and Herzegovina [12] tahini halvah belongs to special group of candy products where quality and minimal conditions for insurance quality and storage of this product are defined. According to current regulations tahini halvah definition reads as follows: It is product obtained from sugar and tahini paste with soapwort root extract addition. Three kinds of product are defined: tahini halvah, black halvah and white halvah. Tahini halvah may be yellow-white to grayish in color, fibrous structure, with sesame oil content at least $22 \%$ from sesame paste. Black halvah is dark, fibrous structure with sesame oil content at least $20 \%$ and with nut fruits and cacao powder added. White halva is hard and sticky mass, white color and with roasted nut fruits added; soapwort root extract is excluded.

To achieve the characteristic flavor, aroma and consistency in the production of tahini halvah may be used citric acid, foaming agents (gelatin), egg white, soy protein extract, soapwort roots extract, chocolate and cocoa powder [12]. Liquid extract of soapwort is often used as food additive in tahini halvah making [13]. As active substance of soapwort liquid extract, saponin affects positively the color and consistency of the halvah and prevents especially the oozing of the oil from halvah in time by acting as an emulsifier [13]. Soapwort extract contains $11.58 \%-19.58 \%$ total saponin which increases importance of soapwort [14]. The classical definition of saponins is based on their surface activity. Many saponins have detergent properties, give stable foams in water, show hemolytic activity, and have a bitter taste [15].

Turkish Standard (TS 2590) [16] is standard of tahini halvah in Turkey and total saponin level must be max $0.1 \%$ in tahini halvah.

Unlike the Turkish Food Codex [16], regulations of confectionary quality in Bosnia and Herzegovina [12] do not address in detail the quality parameters, especially the maximum content of saponins. Besides, only simple kinds of tahini halvah are regulated, while quality of the other specific kinds of this product are not defined. So, the main goal of this paper was to investigate quality of four different tahini halvah samples made under industrial conditions. This study is supposed to contribute better knowing of production and quality of tahini halvah in Bosnia and Herzegovina and promote industrial and strictly controlled making of tahini halvah.

\section{Material and Methods}

Four tahini halvah samples were made in GA-ME-HA d.o.o. company in Sarajevo by traditional recipes, under industrial conditions: standard tahini halvah $(\mathrm{SH})$, tahini halvah with pistachios $(\mathrm{PH})$, tahini halvah with cacao powder added $(\mathrm{CH})$ and black halvah with wheat grits, cacao and nuts $(\mathrm{BH})$.

\subsection{Samples Production}

Samples production were done through the main steps: making sesame-seed paste tahini (seeds cleaning, soaking in salty water for 4-5 hours and washing, centrifuging, roasting on $115-120{ }^{\circ} \mathrm{C}$, cleaning by air stream, grinding, cooling, fine grinding and storing), making soapwort liquid extract from soapwort root (grinding, cooking in closed tanks on $115{ }^{\circ} \mathrm{C}$ until the viscous liquid with $10 \%$ of dry mater and $1,050 \mathrm{~kg} / \mathrm{m}^{3}$ is achieved, and filtration), preparing inverted sugar syrup with liquid soapwort extract added $-3 \mathrm{~L}$ on $100 \mathrm{~kg}$ of sugar in closed tanks under atmospheric pressure, and adjustment and mixing (100-120 rpm). Obtained foam is white and movable due to specific mass reductionfrom 1,300 to $1,100 \mathrm{~kg} / \mathrm{m}^{3}$.

Tahini halvah samples generally were produced by 2 different methods (Figs. 1 and 2). Final products were keeping on $18{ }^{\circ} \mathrm{C}$ to $20^{\circ} \mathrm{C}$ and $50 \% \mathrm{RH}$.

Making black halva sample (BH) is presented on 
Fig. 2. According to main ingredients $\mathrm{BH}$ samples differed regarding to wheat grits and nuts added. Beside those differences, BH samples did not contain soapwort extract and lecithin. Sugar syrup and tahini paste share in this sample was 2:1, while this share in samples $\mathrm{SH}, \mathrm{PH}$ and $\mathrm{CH}$ was 1:1.

\subsection{Chemical Analysis}

Moisture (\%), ash content (\%), crude fats (\%), proteins (\%) (N X 6.25), and sucrose were analyzed [13]. Total carbohydrates (\%) were obtained by calculating. All chemical analyses were performed in triplicate and mean values with standard deviations (S.D.) were reported.

Energy value $(\mathrm{KJ} / 100 \mathrm{~g})$ corresponding to the available energy was calculated using specific coefficients for proteins, lipids and carbohydrates [17].

\subsection{Texture-Hardness}

Textural analysis of TH samples was performed by puncturing using a TA.TX. Plus Texture Analyzer (Stabile Micro Systems England, UK). The analyzer was set to measure force during penetration using cylinder probe $(\mathrm{P} / 0.25 \mathrm{~S})$ and setting travel distance on $15 \mathrm{~mm}$ and test speed $1 \mathrm{~mm} / \mathrm{s}$. The maximum force (N) represented as a measure of hardness. Six measurements per each sample were made and mean values with standard deviations (S.D.) were reported.

\subsection{Sensory Analysis}

TH samples sensory evaluation was carried out by trained 30 assessors (18 females and 12 males) who
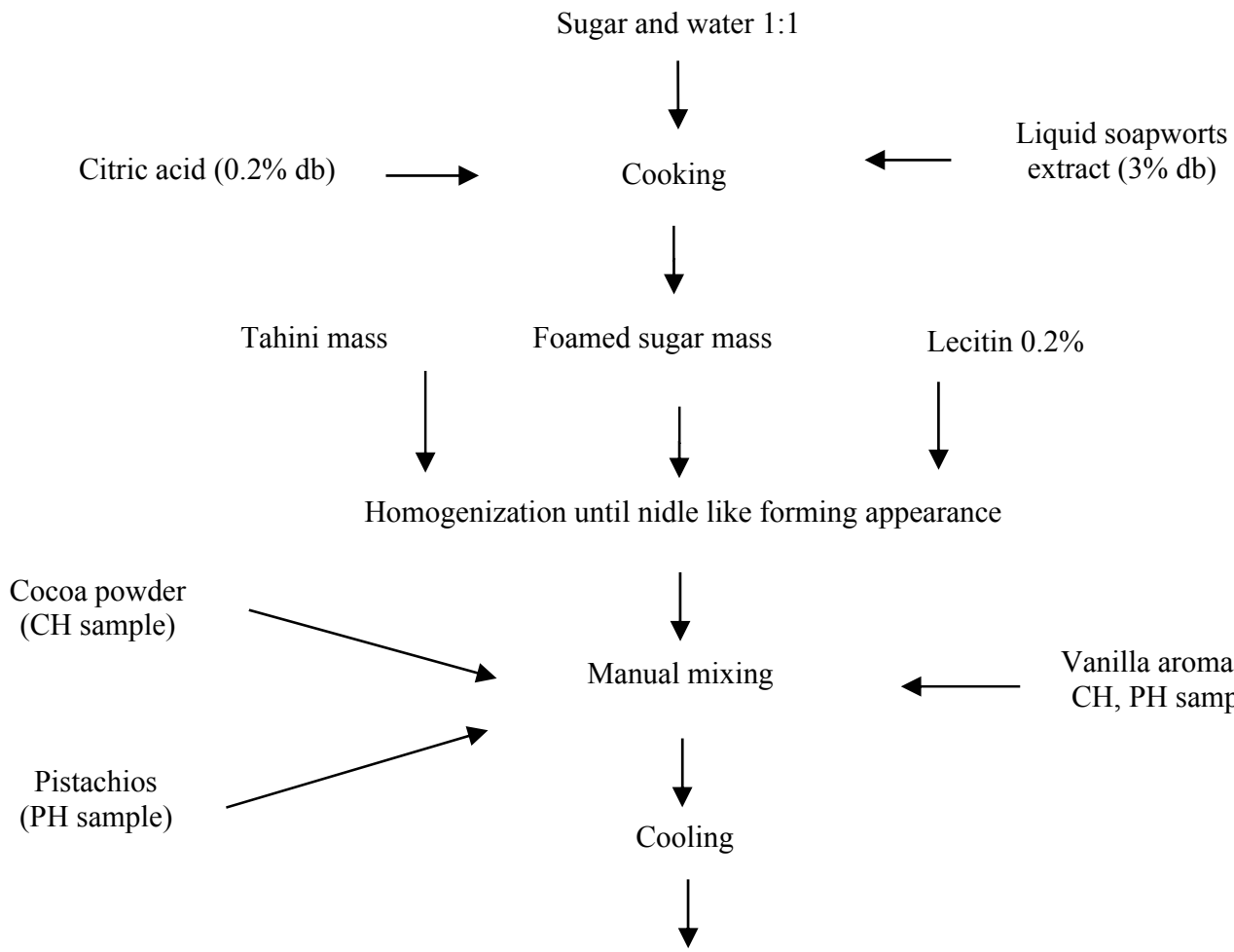

Vanilla aroma (ST,

$\mathrm{CH}$, PH samples)

Weighing and packaging

Final product

Fig. 1 Making tahini halva samples SH, $\mathrm{CH}$ and $\mathrm{PH}$. 


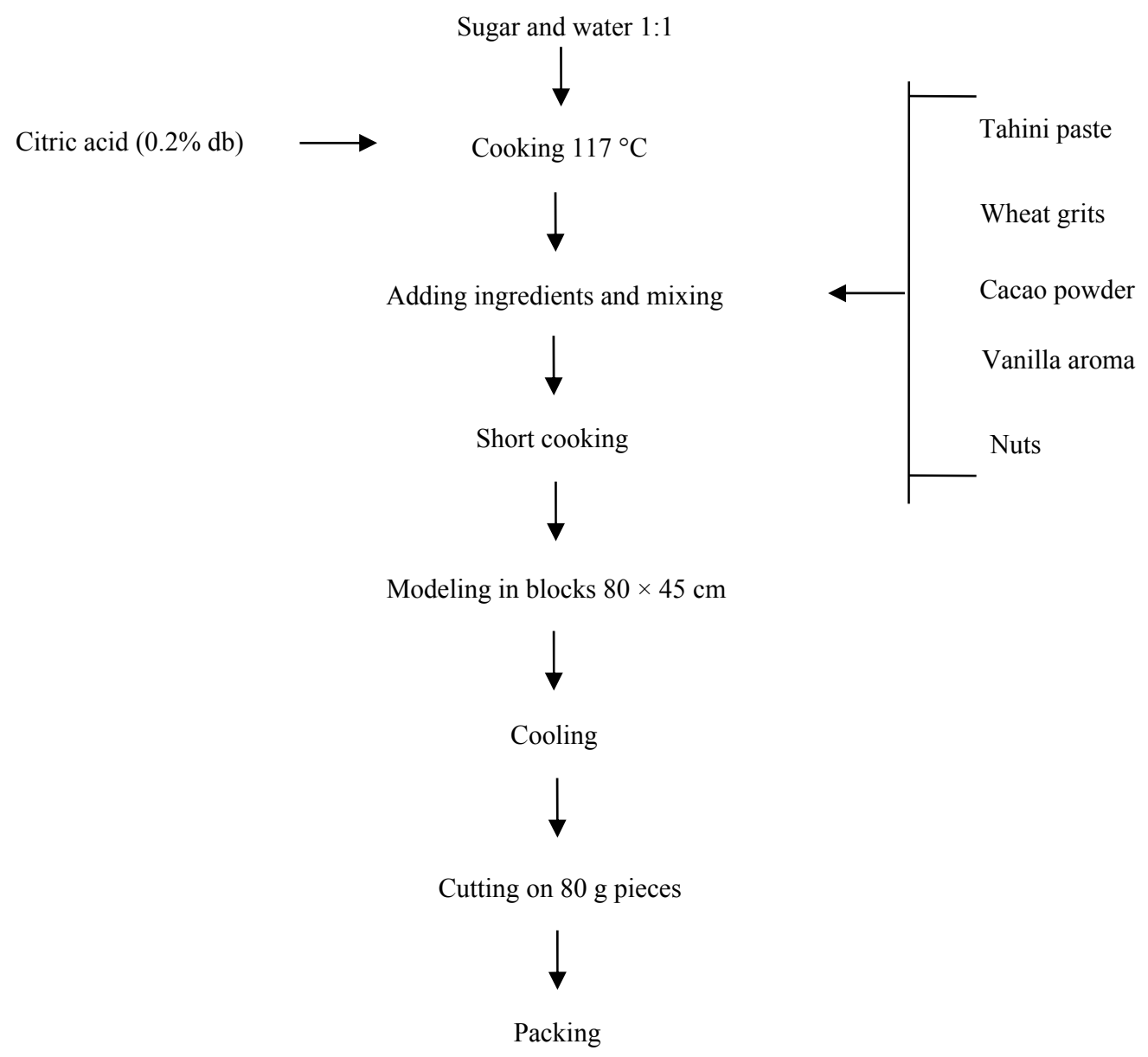

Fig. 2 BH samples making process.

had passed a screening test according to recommendations given in ISO 8586 [18]. They were chosen on the basis of their ability. All of them were employers and students at the Faculty of Agriculture and Food Sciences, University of Sarajevo. Ages ranged from 20 to 48 years old. The panelists were trained in sensory and verbal identification of the taste and odorants.

For the TH samples sensory attributes evaluation a point system was chosen: 1-5 for overall appearance (surface and color), 1-4 for consistency and cross section appearance, 1-3 for odor and 1-8 for taste and melting.

The obtained sensory data were counted from 30 replicates (panelists were considered as replicate). Mean and standard deviation were calculated for all attributes of each sample.

\subsection{Statistical Analysis}

Analysis of variance (one-way ANOVA) was applied. Differences between means of chemical parameters, hardness and sensory values of different TH samples were tested for significance using Fisher's least significant difference (LSD) values.

Multivariate analysis of data by Principal component analysis (PCA) using the statistical computer package StatBox 6.7 (Grimmer Soft, France) was performed.

\section{Results and Discussion}

Chemical parameters and hardness of 4 different $\mathrm{TH}$ samples are given in Tab. 1. Moisture content 
$1.7 \%-7.25 \%$, ash content $0.47 \%-1.56 \%$, crude fat $24.18-33.53 \%$, protein $10.8 \%-12.42 \%$, sucrose 13.4-35.78\% and total carbohydrates $50.96 \%-57.3 \%$ were obtained in this study. Obtained results for $\mathrm{SH}$, $\mathrm{PH}$ and $\mathrm{CH}$ samples are in accordance with study by Ceyhun Sezgin and Artik [13]. Hardness of investigated TH samples was ranged from 11.6 to 57.8 (N).

Moisture content, sucrose and total carbohydrates of $\mathrm{BH}$ were significantly higher $(\mathrm{P}<0.05)$ while the ash and crude fat were significantly lower $(\mathrm{P}<0.05)$ than observed in the others TH samples. Protein content in $\mathrm{BH}$ samples is lower when compared to other s TH samples but significantly differences were not found.

The results of moisture, ash and protein content in samples $\mathrm{SH}, \mathrm{PH}$ and $\mathrm{CH}$ were in unison with Turkish Food Codex [16], while BH sample contained more water for $2.5 \%$ than regulated in this standard (5.0\%).
According to total carbohydrates, the highest value were found in $\mathrm{BH}(57.3 \%)$ and it was significantly different $(\mathrm{P}<0.05)$ from the other $\mathrm{TH}$ samples. The way of production and ingredients, especially wheat grits, added in this sample had significant influence on this parameter.

Results of hardness showed significantly differences $(\mathrm{P}<0.05)$ between $\mathrm{TH}$ samples. The lowest value of hardness in $\mathrm{BH}$ is probably connected with the highest moisture content in this sample.

In accordance with the lowest fat content, the lowest energy value was obtained in $\mathrm{BH}$ sample (Fig. 3).

According to sensory evaluation (Tab. 2) $\mathrm{CH}$ sample was showed the best sensory properties. The possible reason for this may be positive impact of cacao powder with its bitter taste and specific aroma which contribute to more harmonized general acceptability.

Table 1 Chemical parameters and hardness of TH samples.

\begin{tabular}{lllll}
\hline \multirow{2}{*}{ Parameters } & \multicolumn{4}{c}{ Tahini halvah samples } \\
\cline { 2 - 5 } & SH & PH & CH & BH \\
\hline Moisture (\%) & $2.0 \pm 0.2^{\mathrm{a}}$ & $1.74 \pm 0.05^{\mathrm{ab}}$ & $1.7 \pm 0.2^{\mathrm{b}}$ & $7.25 \pm 0.15^{\mathrm{c}}$ \\
Ash content (\%) & $1.56 \pm 0.09^{\mathrm{b}}$ & $1.35 \pm 0.02^{\mathrm{b}}$ & $1.31 \pm 0.01^{\mathrm{b}}$ & $0.47 \pm 0.03^{\mathrm{a}}$ \\
Crude fat (\%) & $32.92 \pm 0.01^{\mathrm{a}}$ & $33.53 \pm 1.56^{\mathrm{a}}$ & $32.96 \pm 0.53^{\mathrm{a}}$ & $24.18 \pm 0.85^{\mathrm{b}}$ \\
Protein (\%) $(\mathrm{N} \times 6.25)$ & $12.22 \pm 1.62$ & $12.42 \pm 1.55$ & $12.28 \pm 0.87$ & $10.80 \pm 1.84$ \\
Sucrose (\%) & $24.11 \pm 2.74^{\mathrm{a}}$ & $13.4 \pm 1.66^{\mathrm{b}}$ & $17.06 \pm 0.88^{\mathrm{c}}$ & $35.78 \pm 1.38^{\mathrm{d}}$ \\
Carbohydrate* & $51.3 \pm 1.78^{\mathrm{a}}$ & $50.96 \pm 3.08^{\mathrm{a}}$ & $51.75 \pm 1.19^{\mathrm{a}}$ & $57.3 \pm 1.99^{\mathrm{b}}$ \\
Hardness (N) & $57.8 \pm 3.0^{\mathrm{a}}$ & $29.2 \pm 3.73^{\mathrm{b}}$ & $21.1 \pm 1.13^{\mathrm{c}}$ & $11.6 \pm 2.13^{\mathrm{d}}$ \\
\hline
\end{tabular}

Different letters in rows indicate significantly different values $(\mathrm{p}<0.05)$; ${ }^{*}$ Calculated by difference.

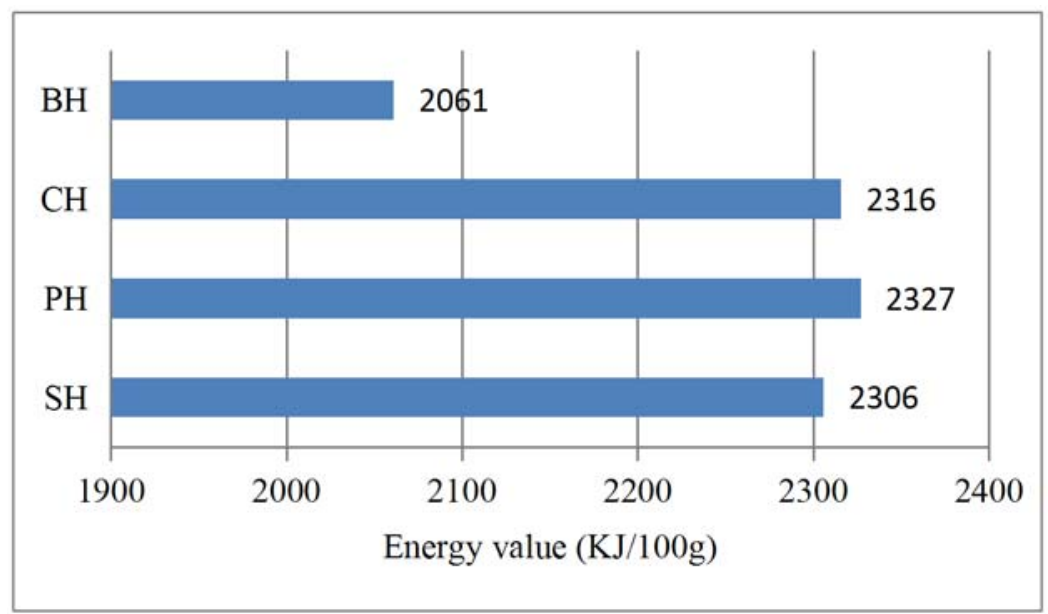

Fig. 3 Energy (KJ/ $100 \mathrm{~g})$ value of TH samples. 
Table 2 Sensory evaluation of TH samples.

\begin{tabular}{llllll}
\hline \multirow{2}{*}{ Attributes } & \multirow{2}{*}{ Max. value } & \multicolumn{4}{c}{ Tahini halvah samples } \\
\cline { 3 - 6 } & & SH & PH & CH & BH \\
\hline Appearance (surfaces and color) & 5 & $4.57 \pm 0.62^{\mathrm{a}}$ & $4.83 \pm 0.38^{\mathrm{b}}$ & $4.90 \pm 0.4^{\mathrm{ab}}$ & $4.83 \pm 0.39^{\mathrm{ab}}$ \\
Consistency, cross section appearance & 4 & $3.2 \pm 0.96^{\mathrm{a}}$ & $3.53 \pm 0.86^{\mathrm{b}}$ & $3.70 \pm 0.79^{\mathrm{ab}}$ & $3.50 \pm 0.68^{\mathrm{ab}}$ \\
Odor & 3 & $2.53 \pm 0.50^{\mathrm{b}}$ & $2.83 \pm 0.38^{\mathrm{a}}$ & $2.80 \pm 0.55^{\mathrm{a}}$ & $2.67 \pm 0.66^{\mathrm{ab}}$ \\
Taste and melting & 8 & $5.0 \pm 0^{\mathrm{b}}$ & $7.4 \pm 0.89^{\mathrm{a}}$ & $7.4 \pm 1.00^{\mathrm{a}}$ & $7.07 \pm 1.31^{\mathrm{a}}$ \\
\hline
\end{tabular}

Different letters in rows indicate significantly different values $(\mathrm{p}<0.05)$.

Table 3 Pearson correlation coefficient (standardized PCA).

\begin{tabular}{llllllllllll}
\hline & $\mathrm{M}$ & $\mathrm{A}$ & $\mathrm{F}$ & $\mathrm{P}$ & $\mathrm{S}$ & $\mathrm{EV}$ & $\mathrm{H}$ & App. & Cons. & Odor & Taste \\
\hline $\mathrm{M}$ & 1 & $\mathbf{- 0 . 9 6}$ & $\mathbf{- 1 . 0 0}$ & $\mathbf{- 1 . 0 0}$ & 0.91 & $\mathbf{- 1 . 0 0}$ & -0.57 & 0.17 & 0.03 & -0.38 & 0.16 \\
$\mathrm{~A}$ & $\mathbf{- 0 . 9 6}$ & 1 & $\mathbf{0 . 9 7}$ & $\mathbf{0 . 9 5}$ & -0.78 & $\mathbf{0 . 9 6}$ & 0.78 & -0.44 & -0.30 & 0.11 & -0.42 \\
$\mathrm{~F}$ & $\mathbf{- 1 . 0 0}$ & $\mathbf{0 . 9 7}$ & 1 & $\mathbf{1 . 0 0}$ & -0.91 & $\mathbf{1 . 0 0}$ & 0.59 & -0.20 & -0.07 & 0.36 & -0.17 \\
$\mathrm{P}$ & $\mathbf{- 1 . 0 0}$ & $\mathbf{0 . 9 5}$ & $\mathbf{1 . 0 0}$ & 1 & $-0,93$ & $\mathbf{1 . 0 0}$ & 0.56 & -0.16 & -0.04 & 0.41 & -0.13 \\
$\mathrm{~S}$ & 0.91 & -0.78 & -0.91 & -0.93 & 1 & -0.92 & -0.24 & -0.18 & -0.26 & -0.70 & -0.23 \\
EV & $\mathbf{- 1 . 0 0}$ & $\mathbf{0 . 9 6}$ & $\mathbf{1 . 0 0}$ & $\mathbf{1 . 0 0}$ & -0.92 & 1 & 0,57 & -0.17 & $-0,04$ & 0.39 & -0.15 \\
H & -0.57 & 0.78 & 0.59 & 0.56 & -0.24 & 0.57 & 1 & -0.91 & -0.82 & -0.52 & -0.88 \\
App. & 0.17 & -0.44 & $-0,20$ & -0.16 & -0.18 & -0.17 & -0.91 & 1 & $\mathbf{0 . 9 7}$ & 0.83 & $\mathbf{0 . 9 8}$ \\
Cons. & 0.03 & -0.30 & -0.07 & -0.04 & -0.26 & -0.04 & -0.82 & $\mathbf{0 . 9 7}$ & 1 & 0.84 & 0.92 \\
Odor & -0.38 & 0.11 & 0.36 & 0.41 & -0.70 & 0.39 & -0.52 & 0.83 & 0.84 & 1 & 0.85 \\
Taste & 0.16 & -0.42 & -0.17 & -0.13 & -0.23 & -0.15 & -0.88 & $\mathbf{0 . 9 8}$ & 0.92 & 0.85 & 1 \\
\hline
\end{tabular}

In bold, significant values (except diagonal) at the level of significance alpha $=0.05$ (Two-tailed test).

Abbreviations: M-moisture; A-ash; F-fat; P-protein; S-sucrose; EV-energy value; H-hardness; App.-Appearance; Cons.-Consistency.

\subsection{Principal Component Analysis (PCA)}

PCA was implemented in order to obtain an overview of the TH samples classification concerning sensory and physicochemical characteristic. The basis for performing of PCA plot was Pearson correlation coefficient (Tab. 3).

When data matrix was subjected to PCA two significant principal components (PCs) were found. They explained the $99 \%$ of data variability. The positive side of the first component (PC1) was determined with most of the physical and chemical properties (hardness, ash content,fat, protein and energy value). Negative side of the (PC1) was determined with moisture content in samples and sucrose content. The second component (PC2) is related to the content of the all tested sensory properties (Fig. 4).

Inspection of Fig. 4 it could be seen that TH samples were located on the three side of biplot. In fact, samples were divided clearly into three groups in the PCA scatter plot according to their sensory and physicochemical characteristics. In the one group are placed the samples $\mathrm{CH}$ and $\mathrm{PH}$ with the best sensory quality. Samples with cacao powder $(\mathrm{CH})$ and pistachio $(\mathrm{PH})$ added in formula are evaluated as the most favourable TH samples by sensory panel.

Opposite of these samples the standard TH sample (SH), was showed the worst sensory quality on all sensory attributes. This sample was also characterized by the highest values of hardness and ash content.

The BH sample was separated from the rest by its higher value of moisture, sucrose and by the lowest value of ash, fat and protein. In addition, $\mathrm{BH}$ sample showed the lowest hardness, as the moisture content is relatively high. Since the moisture content is high and fat content is low, the energy value of $\mathrm{BH}$ is the lowest in comparing to the other $\mathrm{TH}$ samples. 


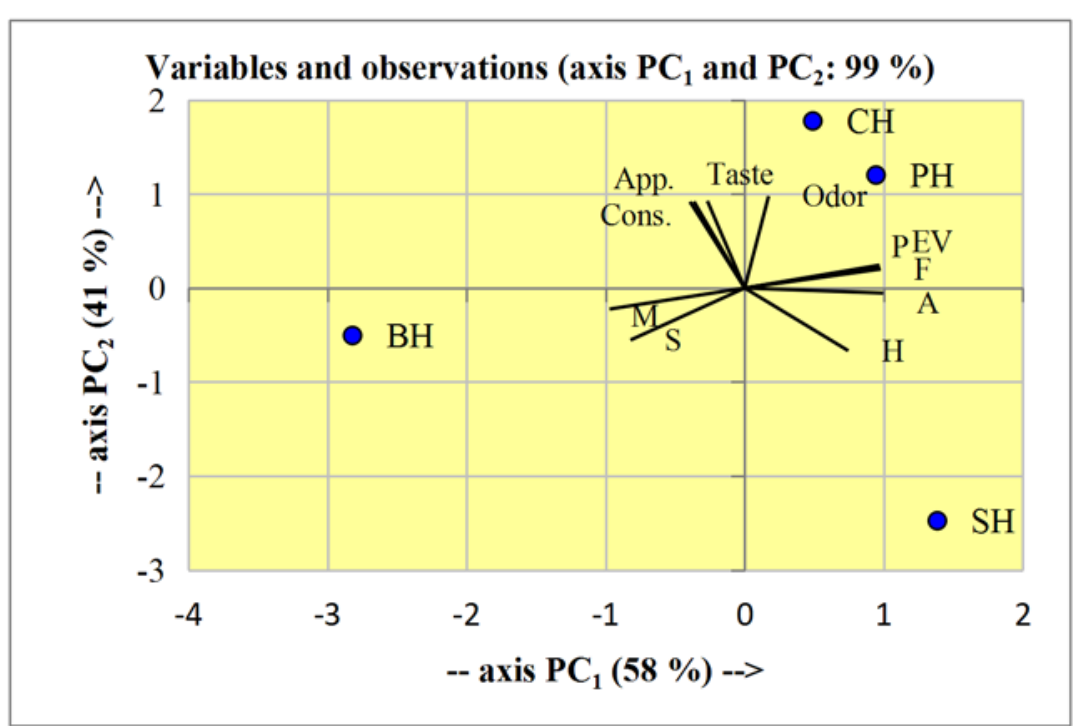

Fig. 4 PCA biplot over $\mathrm{PC}_{1}-\mathrm{PC}_{2}$ of the measured content of sensory and physicochemical characteristic.

(M-moisture; S-sucrose; H-hardness; A-ash; F-fat; P-protein; and EV-energy value) and overall positioning of 4 tahini halvah samples.

\section{Conclusion}

Production of tahini halvah under industrial and strictly controlled conditions is necessary to get standard product with uniform and good quality. However, regulation in Bosnia and Herzegovina considering this product should improve and primarily include the limit of saponin content and sucrose, also. Besides this, all possible additions in formula should define and regulate the minimum content in final product.

Next researches should conduct to improve sensory characteristic of tahini halvah by reducing sweetness, which would lead to reducing energy value, and by adding more valuable ingredients in formula. A good choice could be substitution sucrose with a kind of adequate sweetener. Nevertheless, permanent education of consumers to select high value nutritive food and estimate food quality is needed, especially regarding to confectionary products.

\section{References}

[1] Goldoni, L. 2004. Technology of Confectionary Products, II Part Candy Products, Kugler, Zagreb, Croatia, 219-23. (in Croatian)
[2] Accessed 06/11/2015. Available from http://www.akta.ba/en/Vijest/investments/gornji-halvadzi luk-project-the-confectionary-bazaar-returns-to-sarajevo/ 48848\#ad-image-0.

[3] Gavrilović, M. 2003. "Technology of Confectionary Products." Tehnološki fakultet, Univerzitet Novi Sad, Serbia, 430-2. (in Serbian)

[4] Anilakumar, K. R., Pal, A., Khanum, F., and Bawa, A. S. 2010. "Nutritional, Medicinal and Industrial Uses of Sesame (Sesamumindicum L.) Seeds-An Overview." Agriculturae Conspectus Scientificus 75: 159-68.

[5] Ercan, A. G., Taskin, K. M., Turgut, K., Bilgen, M., and Firat, M. Z. 2002. "Characterization of Turkish Sesame (Sesamumindicum L.) Landraces Using Agronomic and Morphologic Descriptors." Akdeniz Universitesi Ziraat Fakultesi Dergisi 15: 45-52.

[6] Unal, M. K., and Yalcsn, H. 2008. "Proximate Composition of Turkish Sesame Seeds and Characterization of Their Oils." Grasas Aceites 59: 23-6.

[7] Sirato-Yasumoto, S. M. J., Katsuta, Y., Okuyama,Y., and Takahashi, I. T. 2001. "Effects of Sesame Seed Rich in Sesamin and Sesamolin on Fatty Acid Oxidation in Rat Liver.” J. Agri. Food Chemistry 49: 2647-51.

[8] Wichitsranoi, J., Weerapreeyakul, N., Boonsiri, P., Settasatian, C., Settasatian, N., Komanasin, N., Sirijaichingkul, S., Teerajetgul, Y., Rangkadilok, N., and Leelayuwat, N. 2011. "Antihypertensive and antioxidant effects of dietary black sesame meal in pre-hypertensive humans." Nutritional Journal 10: 82-8.

[9] Tunde-Akintunde, T. Y., Oke, M. O., and Akintunde, B. O. 2012. "Sesame Seed, Oilseeds." In Tech, Available 
from

http://www.intechopen.com/books/oilseeds/sesame-seed.

[10] Makinde, F. M., and Akinoso, R. 2013. "Nutrient Composition and Effect of Processing Treatments on Anti-nutritional Factors of Nigerian Sesame (Sesamumindicum Linn) Cultivars." International Food Research Journal 20 (5): 2293-300.

[11] Fedosov, S. 2012. "Technological aspects of traditional foods in BaSeFood." Traditional Food International (TFI-2012), Cesena, Italy.

[12] 2012. Regulations on products similar to chocolate, cream products and candy. Official Gazette Bosnia and Herzegovina 78: 49. (in Bosnian)

[13] CeyhunSezgin, A. E., and Artik, N. 2010. "Determination of Saponin Content in Turkish Halvah by Using HPLC." Advance Journal of Food Science and Technology 2 (2): 109-15.

[14] Battal, H. 2002. "A Research on the Production of
Soapwort Extract.” Ankara University Graduate School of Natural and Applied Sciences, Ankara, Turkey, 44.

[15] Šošević, S. 2012. Biološka aktivnost saponini naprimjeruzlatice, Hrana u zdravlju I bolesti, znanstveno-stručni časopis zanutricionizam I dijetetiku 1 (2): 48-51. (in Bosnian)

[16] Anonymous. 1998. Standard of Turkish Tahini Halvah, T. S. 2590, Institute of Turkish Standards, Ankara, Turkey, 10.

[17] Astrup, A. 2009. “Tremblay, Energy Metabolism.” In Introduction to Human Nutrition, 2nd edition. edited by Gibney, M. J., Lanham-New, S. A., Cassidy, A., and Vorster, H. H. Wiley-Blackwell, 31.

[18] EN ISO 8586. 2014. Sensory Analysis-General Guidelines for the Selection, Training and Monitoring of Selected Assessors and Expert Sensory Assessors (ISO 8586:2012). International Organization for Standardization. 